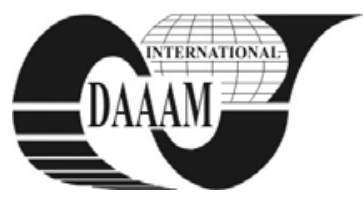

Annals of DAAAM for 2011 \& Proceedings of the 22nd International DAAAM Symposium, Volume 22, No. 1, ISSN 1726-9679 ISBN 978-3-901509-83-4, Editor B. Katalinic, Published by DAAAM International, Vienna, Austria, EU, 2011 Make Harmony between Technology and Nature, and Your Mind will Fly Free as a Bird Annals \& Proceedings of DAAAM International 2011

\title{
FINITE ELEMENT ANALYSIS OF AN OUTER BEARING BUSH OF A KAPLAN TURBINE
}

\author{
MICLOSINA, C[alin] - O[ctavian]; CAMPIAN, C[onstantin] V[iorel] \& FRUNZAVERDE, D[oina]
}

\begin{abstract}
The paper presents the finite element analysis of the outer bearing bush of a Kaplan turbine. In order to obtain von Mises stress plot, the forces are applied on the links of the $3 D$ model of the runner blade operating mechanism, the motion is simulated, the meshing of bush model is done and the stress calculus is performed. For modeling and simulation, SolidWorks 2010 software was used.

Key words: Kaplan turbine, outer bearing bush, finite element analysis, von Mises stress
\end{abstract}

\section{INTRODUCTION}

The main characteristic of the Kaplan turbine is the possibility to modify the rotor blades angles in order to achieve high efficiency in different water flow conditions.

The runner blade operating mechanism consists of a fork head driven by a hydraulic servomotor, a connecting rod and the pin lever - trunnion - blade subassembly. This subassembly is borne by the rotor's body through an outer bush and an inner bush.

While functioning, failures occur due to high loads or fatigue phenomenon.

Studies on the failure of different parts of Kaplan turbines were made: runner blade (Frunzaverde et al., 2010), pin lever (Pittner et al., 2010).

This paper proposes the finite element analysis of the outer bearing bush. The loads during motion are computed and imported in a static study, which is solved using the finite element method.

\section{3D MODEL OF RUNNER BLADE OPERATING MECHANISM}

The 3D model of runner blade operating mechanism is presented in fig. 1 (Miclosina et al., 2011).

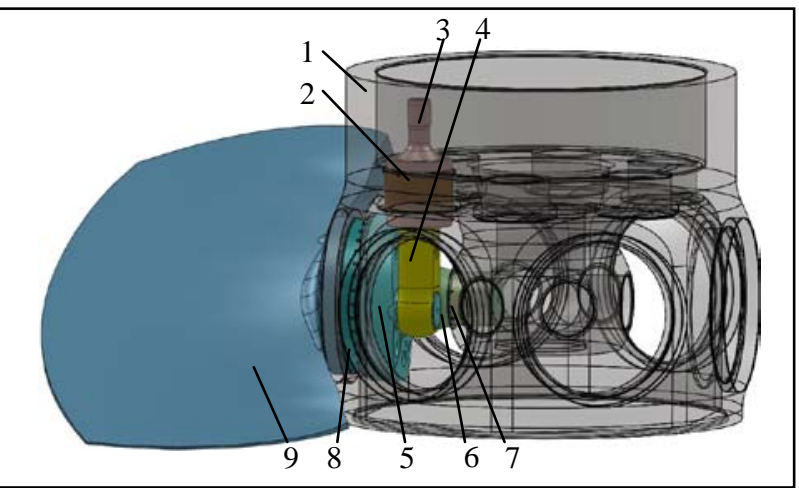

Fig. 1. 3D model of runner blade operating mechanism

The component parts are as follows: 1 - hub; 2 - bush; 3 - fork head; 4 - connecting rod; 5 - pin lever; 6 - trunnion; 7 - inner bearing bush; 8 - outer bearing bush; 9 - blade. All parts have assigned materials. From SolidWorks materials library, tin bearing bronze is chosen for the outer bearing bush.

\section{MOTION ANALYSIS OF RUNNER BLADE OPERATING MECHANISM}

The blade angle at the beginning of motion is $\varphi=8,47\left[^{\circ}\right]$. The dependence displacement of fork head vs. time is presented in fig. 2 (Miclosina et al., 2011).

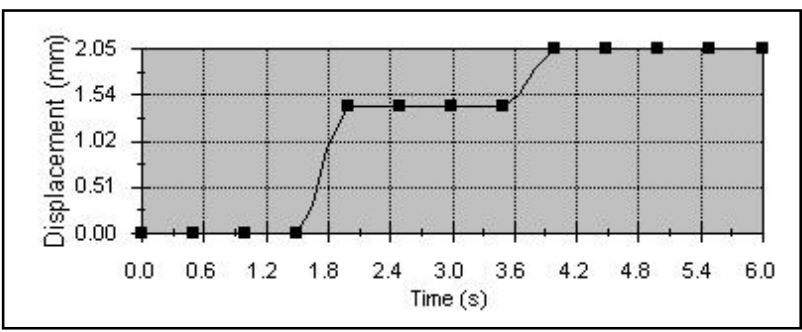

Fig. 2. Dependence displacement of fork head vs. time

The forces that act on mechanism links are as follows: axial force on the blade $\mathrm{F}_{\mathrm{ax}}=1,771 \cdot 10^{6}[\mathrm{~N}]$, tangential force on the blade $F_{t}=1,025 \cdot 10^{6}[\mathrm{~N}]$, centrifugal force of the pin lever trunnion - blade subassembly $\mathrm{F}_{\mathrm{c}}=4,070 \cdot 10^{6}[\mathrm{~N}]$. These forces can be applied in points (fig. 3) or on surfaces (Miclosina et al., 2011). The action force $F_{a}$ acts on surface $S$ of the fork head.

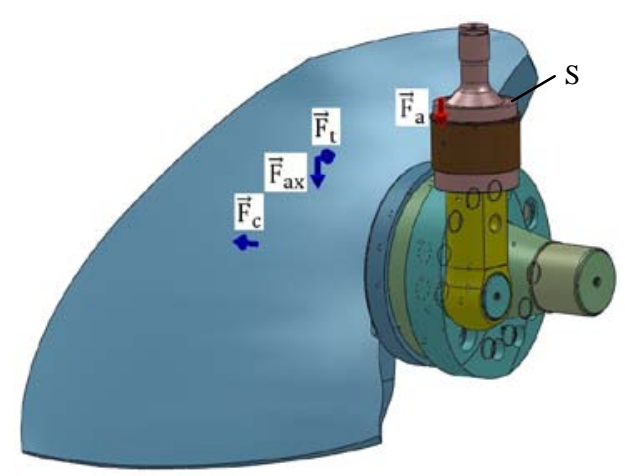

Fig. 3. Forces acting on mechanism links

The variation of magnitude of action force $F_{a}$, computed by SolidWorks software, is shown in fig. 4.

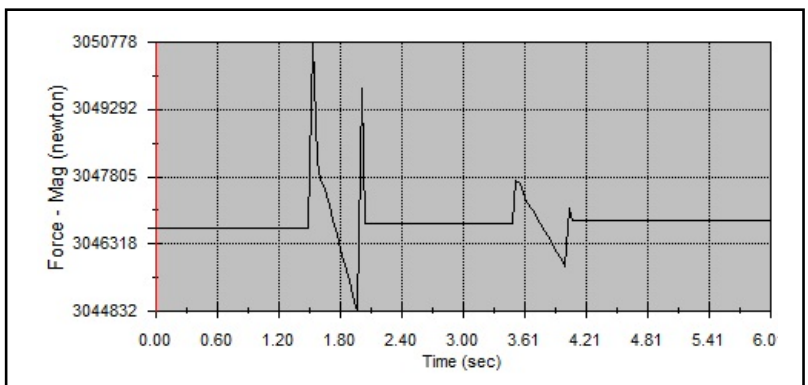

Fig. 4. Variation of action force magnitude 


\section{FINITE ELEMENT ANALYSIS OF THE OUTER BEARING BUSH}

For the stress calculus, the loads on the outer bearing bush are imported from motion analysis for the whole motion period.

In numerical simulation, stress values depend on mesh parameters (Bordeasu et al., 2009), (Hursa et al., 2007).

Standard mesh with automatic transition option was used. The values for global mesh sizes (GMS) were chosen as follows: 22, 25, 28, 31, 34 and 37 [mm]. Mesh with global size 22 [mm] applied on outer bearing bush is presented in fig. 5 .

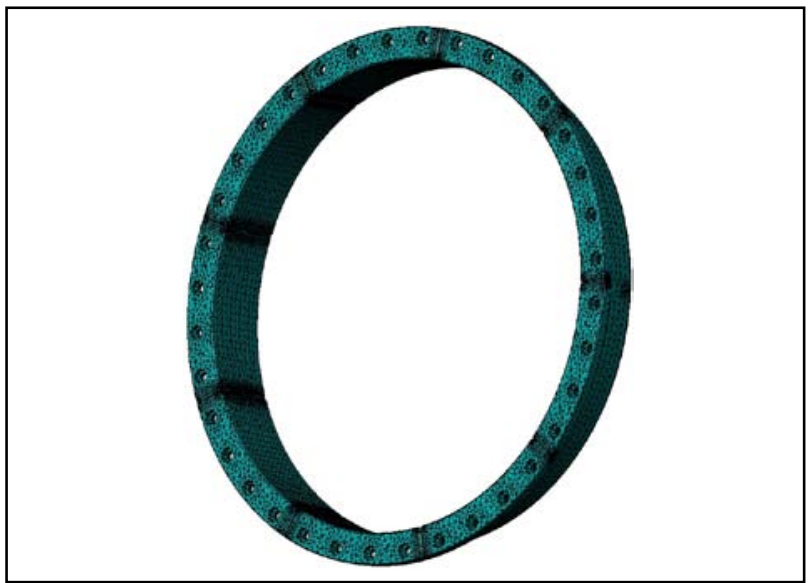

Fig. 5. Mesh applied on outer bearing bush

Examples of meshing with different global sizes are presented in fig. 6 .

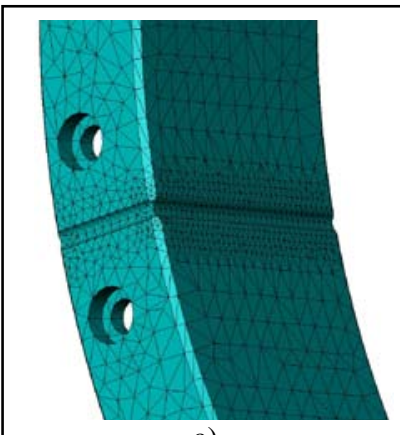

a)

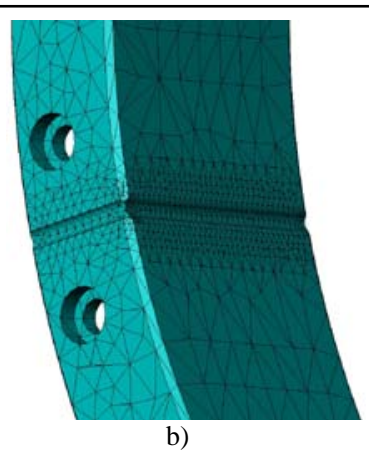

b)
Fig. 6. Different global mesh size: a) 22 [mm]; b) 37 [mm]

After the numerical solving of the study, the plot for von Mises stress is obtained (fig. 7).

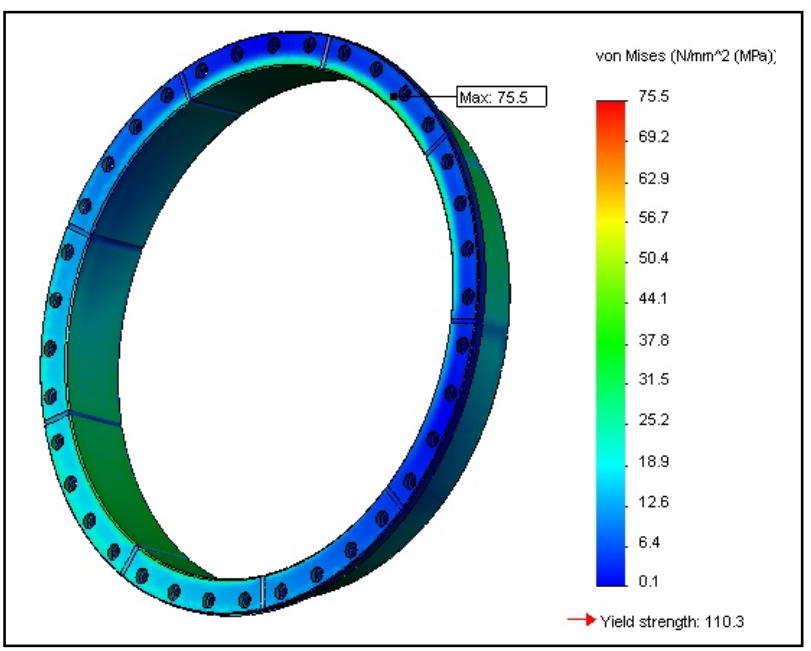

Fig. 7. Plot for von Mises stress for global mesh size 22 [mm]
For different global mesh sizes, different maximum values for von Mises stress were obtained, as shown in fig. 8 .

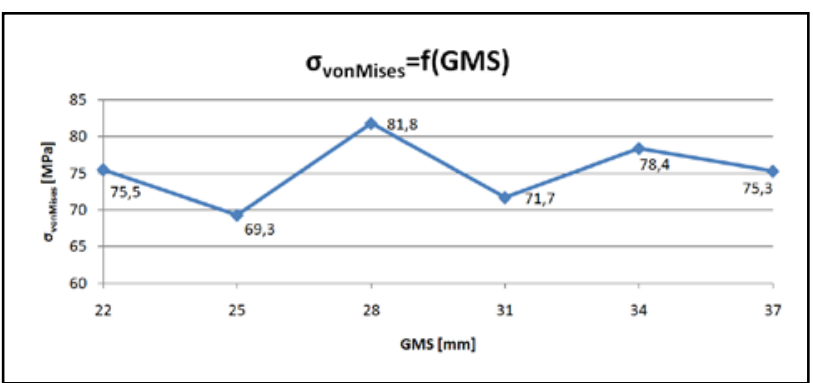

Fig. 8.Values of maximum von Mises stress depending on global mesh size (GMS)

\section{CONCLUSIONS}

Using SolidWorks Simulation module, the maximum values of von Mises stress were computed for the outer bearing bush. These values vary between 69,3 and 81,8 [MPa] and are lower than yield strength (110,3 MPa) for global mesh sizes between 22 and 37 [mm].

As further research, a fatigue analysis of outer bearing bush follows.

\section{ACKNOWLEDGEMENTS}

The work has been co-funded by the Sectoral Operational Programme Human Resources Development 2007-2013 of the Romanian Ministry of Labour, Family and Social Protection through the Financial Agreement POSDRU/89/1.5/S/62557.

\section{REFERENCES}

Bordeasu, I.; Popoviciu, M.O.; Marsavina, L.; Voda, M.; Negru, R. \& Pirvulescu, L.D. (2009). Numerical Simulation of Fatigue Cracks Initiation and Propagation for Horizontal Axial Turbines Shafts, Annals of DAAAM for 2009 \& Proceedings of the $20^{\text {th }}$ International DAAAM Symposium, $25-28^{\text {th }}$ Nov. 2009, Vienna, Austria, ISSN 1726-9679, Katalinic, B. (Ed.), pp. 407-408, published by DAAAM International Vienna

Frunzaverde, D.; Campian, V.; Nedelcu D.; Gillich G.-R. \& Marginean, G. (2010). Failure Analysis of a Kaplan Turbine Runner Blade by Metallographic and Numerical Methods, Proceedings of 5th IASME/WSEAS International Conference on Continuum Mechanics, 23-25 Feb. 2010, Cambridge, England, ISBN 978-960-474-158-8, pp. 60-66

Hursa, A.; Rolich, T.; Somodi Z. \& Rogale, D. (2007). A Study of Mesh Influence In Numerical Modelling of Stress Concentration In Textile, Annals of DAAAM for 2007 \& Proceedings of the 18th International DAAAM Symposium, 24-27th October 2007, Zadar, Croatia, ISSN 1726-9679, ISBN 3-901509-58-5, Katalinic, B. (Ed.), pp. 341-342, published by DAAAM International Vienna

Miclosina, C.-O.; Campian, C.V.; Frunzaverde, D. \& Cojocaru, V. (2011). Analysis of an Outer Bearing Bush of a Hydropower Plant Kaplan Turbine Using Finite Element Method. Proceedings of the $5^{\text {th }}$ WSEAS International Conference on Renewable Energy Sources (RES '11), 1-3 July 2011, Iasi, Romania, ISBN 978-1-61804-012-1, Gavriluta, N. et al (Ed.), pp. 221-224, published by WSEAS Press

Pittner, A.-M.; Campian, C.V.; Nedelcu, D.; Frunzaverde, D. \& Cojocaru, V. (2010). Stress Concentration Factors for Pin Lever of Runner Blade Mechanism from Kaplan Turbines. Proceedings of $3^{\text {rd }}$ WSEAS International Conference on Engineering Mechanics, Structures, Engineering Geology, 22-24 July 2010, Corfu Island, Greece, ISSN 1792-4294, Martin, O. (Ed.), pp. 181-185, published by WSEAS Press 